\title{
COMMUNICATION SKILLS IN THE SCIENTIFIC AND TECHNOLOGICAL SPHERE: SOME BASIC SKILLS AND STRATEGIES TO START WRITING DOCUMENTS
}

M. PaZ Kindelán

E.T.S. Ingeniera de Minas

Universidad Politécnica de Madrid

\section{AbSTRACT}

It is widely accepted today that the general standard of the written communication of scientists and technologists is low. This is apparent both in higher education and in industry. In order to remedy this deficiency, Communication Skills training is regarded as a crucial component of university curricula and hence is becoming gradually integrated into academic degree coursework. Subjects such as the techniques and structures of technical writing as well as those of effective oral presentation are the main constituents of this training. Surveys carried out by various scholars and experts in the field show that writing is rated as one of the most important skills required by practising engineers. The aim of this article is to focus attention on the three interactive constructs needed for effective writing and communication in general: the purpose for communicating; the audience to whom one communicates; and the selection and organisation of content to be communicated. The analysis of extensive coursework of engineering students at the School of Mining (Madrid) has allowed me to devise a communicative methodology to guide their written work. This method is student-centred and basically relies on the use of several strategies or tactics directed at selecting and arranging information appropriately within a specific genre. The outcome shows that students have gained awareness of 
the conventions and formats of some characteristic genres in the academic domain and have ultimately improved their writing skills. Although there was not a testable hypothesis, this practice of strategies demonstrated qualitatively an advance in their ability to produce a good written piece of work.

\section{INTRODUCTION}

Over the last decade, data on science and engineering education has been collected from various departments in British and American institutes of higher eduation. This evidence suggets that the technical student all too often reads superficially and fails to take the meaning. S/he seems to find self-expression in writing difficult, lacks appropriate forms of expression for particular situations and, in general, has a poor command of English. This research also reveals that the faculty of these instituions have noticed these weaknesses in the students' ability to express themselves orally and in writing (see Railton 1984; Turk \& Kirkman 1992; and Jenkins, Jordan \& Weiland 1993).

Although the primary training and interests of science and engineering students lie in technical areas, skills developed in their fields will be unnoticed and unappreciated unless they can communicate to others what they are doing and why it is important. From this perspective, Communication Skills are not only necessary but, as Huckin and Olsen (1991:3) state, they are critical tools for success, even survival, in real world environments.

The focus on Communication Sills was first developed with the L1 speaker in mind. He would not only have native speaker competence but also have had a thorough formal education in the mechanics of the language. With such a concern in mind, Communication Skills could concern itself almost exclusively with how to achieve greater efficiency in communication, especially in the areas of science, technology and management. Although English is not the L1 in Spain, the majority of students in higher education receive formal instruction in this foreign language, being the main vehicle for interpersonal and working relations worldwide. Native-speaker proficiency cannot therefore be assumed, but communicative competence involving a series of written and oral skills is considered essential in an EFL situation. Leaners are expected to have some grounding in core English and the task in ESP will be teaching them to extend or even adapt this competence to particular fields of work or study. At tertiary level, Communication Skills become crucial since undergraduates need to be prepared more specifically for the positions that they will occupy in their future careers in industry and management, and there is no doubt that English plays a major role in everyday working transactions. 
In fact, most surveys conducted in renowned industries on the education of engineers (see Keenan \& Newton 1984; Huckin \& Olsen 1991) demonstrate that a major part of their professional success relies on their ability to transmit the results of their work to technical and non-technical colleagues, clients and subordinates in a meaningful and effetive way. The findings of such surveys show that Communication Skills rank higher than most other types of skill, being arranged in order of importance as follows:

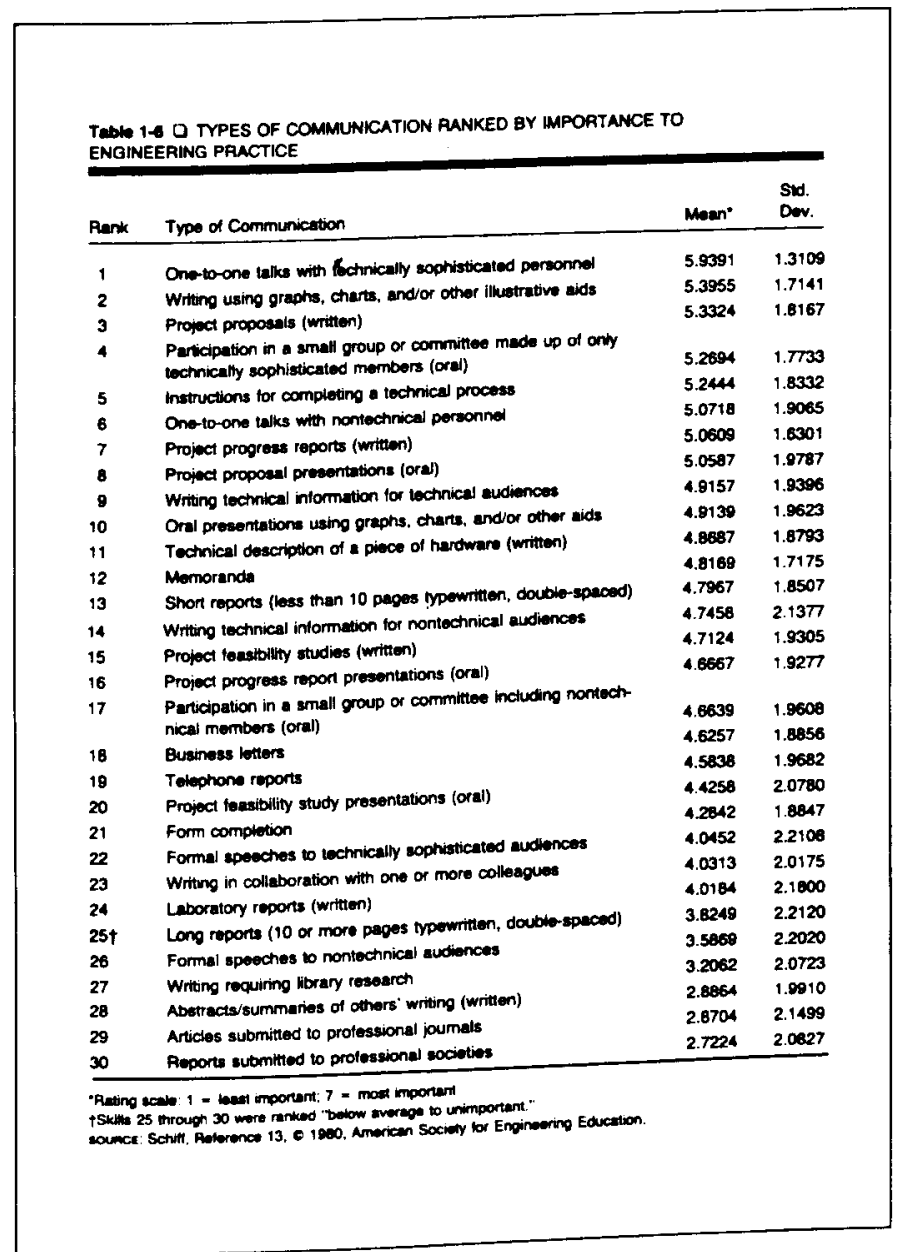

Figure 1. Types of communication ranked by impotance to engineering practice. Huckin \& Olsen 1991:12. 
As can be seen in figure 1, technical writing along with oral skills is one of the major categories which often receives the highest rating since it is regarded as critical or very important to success.

In response to this concern, a good number of science and engineering departaments both in British and Amercian universities have integrated a course in technical writing into the academic curriculum (see Hendricks \& Pappas 1996). The primary objective of this course is to raise undergraduate student writing and communication skills above the level expected by future employers. Underlying these special programmes is the belief that all writing and oral communication are creative activities - acts of thinking, conceptualising, organising, and drafting ideas into an accessible form for a specific audience.

At Spanish universities, the need for writing skills in academic coursework is also an essential demand (Palacios 1994: 210). Recent research carried out by lecturers of the Departament of Applied Linguistics at Universidad Politécnica de Madrid has shown that writing and speaking in English are the two communication skills most needed by:

- Professors of the technical schools and faculties: to write and publish scientific pappers in international journals as well as to attend conferences and meetings in technical subjects.

- And also by students: to get a job (for oral interviews, written applications, etc.) and to be promoted within a company.

Consequently, if non-native speaking graduates do not want to be isolated from the real world, they need to communicate with representatives of other international companies and also with their colleagues to keep abreast of technological developments and to share research on international projects such as ESPRIT or EUREKA.

So acute has this need become that, in order to improve graduates' Communication Skills within their working environments, departaments of Science and Technology at various Spanish universities have offered a wide range of post-graduate and doctorate degree courses to meet this requirement. These courses deal with subjects such as: composing strategies; the teaching of reading comprehension and oral communication; and also using English as an access tool to scientific documents (see list of Spanish university courses through Internet) ${ }^{\prime}$.

' Internet: http: \www.rediris.esłrecursosłcentros luniv.es.html. 
For example, the Departament of Linguistics Applied to Science and Technology at Universidad Politécnica (Madrid) has initiated, during the last few years, two doctorate degree courses dealing with oral presentations and writing in technical and professional settings. In fact, the new programme ofered for the period 2000/02 includes various topics within this field:

- Oral presentations in professional settings.

- Technical and professional writing.

- How to write research articles in English to be published in scientific and technical journals.

The courses are open to students of other programmes, specialities and even universities. One of the objectives is to expand the offer in the near future to address various topics within this field (e.g. Genres in E.S.P.; The Technical Report; and the Technical Research Article), and eventually provide graduates and professionals withsuitable training in Communication Skills of then lacking in their former education.

During their academic studies, a science and technology student is engaged in a process of storing information made available to them by reading, note-taking, listening to lectures, participating in seminars, interpreting data, carrying out experiments and recording them, memorising, or simply noting down where sources can be recalled from. The process of information retrieval, storage, organistaion and transmission carries on throughout the course of their professional career, even if it is not tested under formal examination conditions. In fact, during their professional lifetime, they spend a lot of time assimilating information by themselves and communicating it to others.

These activities depend on acquiring good Communication Skills. There is little difference between the main communication skills needed in the academic world and those required in industry as figure 2 below shows. The main differences concern the respective audiences.

The genres required in the technical and scientific field vary little from the undergraduate to the professional: perhaps within the structure of a company or organisation, proposals, memos and letters are more often used. The writing purposes regarded as a priority in these two spheres fall into three main categories: inform; define/describe; and persuade. At an academic level, the emphasis is laid more on informing the reader. The skills needed are practically the same from undergraduates to professionals, from the instructor to a wide range of prospective readers. But between the academic and industrial domains, there is a notable contrast in the audience. Why?

At school or college, writing is a process of display addressed to teachers who already know the information whereas in professional life, the aim and audience 


\begin{tabular}{|c|c|c|c|}
\hline & Undergraduate & Graduate & Professional \\
\hline Genres & $\begin{array}{l}\text { Reports } \\
\text { Letters } \\
\text { Resumes } \\
\text { Outlines } \\
\text { Summaries }\end{array}$ & $\begin{array}{l}\text { Reports } \\
\text { Joumal articles } \\
\text { Thesis } \\
\text { Abstracts } \\
\text { Letters } \\
\text { Resumes } \\
\text { Curriculum Vitae }\end{array}$ & $\begin{array}{l}\text { Reports } \\
\text { Memos } \\
\text { Letters } \\
\text { Proposals } \\
\text { Articles } \\
\text { Resumes } \\
\text { Etc. }\end{array}$ \\
\hline Andience & The instructor & $\begin{array}{l}\text { The instructor } \\
\text { A thesis committee } \\
\text { Fellow specialists }\end{array}$ & $\begin{array}{l}\text { Supervisor } \\
\text { Managers } \\
\text { Cliente } \\
\text { Co-workers } \\
\text { Sales dept. } \\
\text { Investors } \\
\text { Government } \\
\quad \text { agencies } \\
\text { Fellow } \\
\text { professionals } \\
\text { Etc. }\end{array}$ \\
\hline Purpose & To inform & $\begin{array}{l}\text { To inform (and } \\
\text { persuade?) }\end{array}$ & $\begin{array}{l}\text { To inform } \\
\text { To define and } \\
\text { describe } \\
\text { To persuade }\end{array}$ \\
\hline Skills & $\begin{array}{l}\text { Summarizing } \\
\text { Paraphrasing } \\
\text { Describing } \\
\text { Comparing } \\
\text { Explaining/inter- } \\
\quad \text { preting }\end{array}$ & $\begin{array}{l}\text { Summarizing } \\
\text { Paraphrasing } \\
\text { Describing } \\
\text { Comparing } \\
\text { Explaining/inter- } \\
\quad \text { preting } \\
\text { Synthesizing } \\
\text { Critiquing }\end{array}$ & $\begin{array}{l}\text { Summarizing } \\
\text { Paraphrasing } \\
\text { Describing } \\
\text { Comparing } \\
\text { Explaining/inter- } \\
\quad \text { preting } \\
\text { Synthesizing } \\
\text { Critiquing } \\
\text { Persuading } \\
\text { Recommending } \\
\text { Etc }\end{array}$ \\
\hline
\end{tabular}

Figure 2. Technical/Scientific Writing. Reprinted by permission of Thomas Huckin 1994.

for writing are often different. For the first time, the new professional scientist or engineer is writing for people who do not know the information: clients, investors, managers, etc. The readers do not want to assess; they want to learn and use the information for their own purposes. Therefore, tactics must change. The main aim is to ease the reader's burden by concentrating on simplicity and clarity of language and the minimum of information to be conveyed, instead of embedding it in sophisticated language, with complex structures and pompous vocabulary.

Thus, there are two crucial aspects of communicating technical and scientific information which must be considered first: any piece of writing has a definite purpose and is directed to a particular audience. 


\section{Purpose AND AudiEnce}

In technical writing, the purpose is generally to inform, to define or describe, and/or to demostrate. Most topics can be treated in one of these ways, depending upon the situation you find yourself in. Often, you are simply informing like in the following figure advertising a machine:

\section{PERKIN-ELMER Lambda 1A Spectrophotometer}

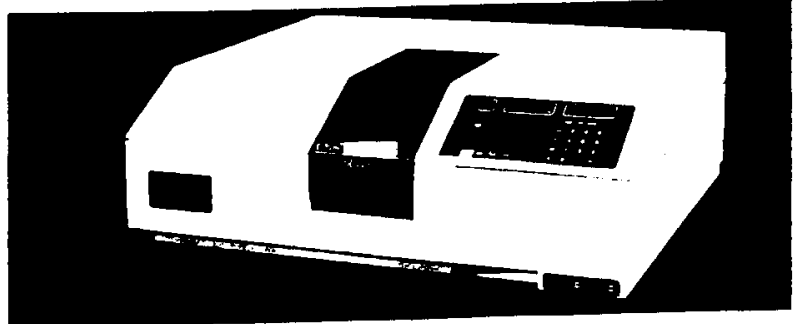

Fipure 1. Perkin-Eimer Lombda iA

Perkin-Elmer's Lambde $1 \mathrm{~A}$ represents the cost. reduced version of the highty roliable and successful Lambdo 1 .

It is a single beam, high performance spectrophotometer which is adaptable to a wide ranoe of analytical methods. This totally microprocessor controlled spectrophotometer provides optimum operating conditions by simple keystroke commands. The extended wavelength range of 190 to $900 \mathrm{~nm}$ with a spectral bandpass of $2 \mathrm{~nm}$ makes it the ideal, general purpose spectrophotometer for the laboratory demanding superior pertomance at a reasonable price.

\section{Foatures}

Thres Operating Modes

Lambda ia is capabie of reading samples in $\% \mathbf{T}$, Absorbance, or directly in concentration units

In the Concentration Mode, the concentration factor (the number by which the absorbance must be multiplied to obtain the concentration can be determined automatically by the instrument or entered manually by the operator.

- Mieroproceseor Controtled Lambde IA is totally controlled by a microprocessor - no filters, lamps, or detectors to change throughout the entire wavelength range.

The operator simply deprasses the appropriate keys to set the operating conditions and the microprocessor automaticaliy and precisely sels the desired parameters.

\section{Nine Memory Locations}

Nine con plete sets of operating parameters can be stored in memory tlles within Lambda $1 \mathrm{~A}$ us. ing the Saia Memory teature.

By recalling a speclfic memory lile, the instru ment automatically seis the operatilig

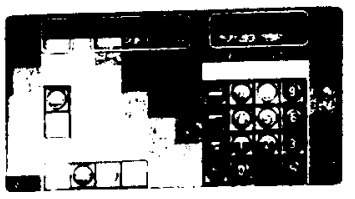

Fioure 2. Koy Pad Pariel

parameters as they were onginalty stored. The need to reenter operating parameters for routine analyses is eliminated.

Integration of Absorbance Value A simple keypad command allows the absor. bence value of a sample to be averaged (integrated) over a four-second interval.

Wide Selection of Accessorins

Inlomele Printer for hard copy printout of results and operating parameters.

- Super Sipper (heated or unteated) auto sampler for automatic sample transler to instrument.

- Multi Sampier for totally automatic sampling for up to 210 samples.

- Integrnting Gel Scemer for reading and in tegrating $10 \mathrm{~cm}$ disc gels. Requires R100A tegrating

R100A Recorder for graphical presentation of time drive analysis, gel scans, or bar graph time drive analysis, ges scans, or bats with Super Sipper.

presentation of results with Super sipperatoric reading of up to 5 cells at speclfic intervals - temperature control available.

- R5232C Intorface for bidirectional communica tion with a computer.

Figure 3. An example of an informative advertisement. 
This is an example of a catalogue description written in formal technical language. It includes statements about function, details of its main features and specifications of built-in accessories. The purpose of the description is primarily to make the reader aware of the existence of this new version of a spectrophotometer.

However, you may not be merely describing a machine, but trying to demonstrate its superiority with respect to other machines of the same type. To do so, you will need to give sound arguments by showing, perhaps, how your machine is more economical and easier to maintain than other machines. So you will be persuading! You discover then that, although your ostensible purpose was initially to inform about a mechanism, other unstated purposes are required to complete the overall task.

Figure 4 is a persuasive catalogue description which uses persuasive catalogue description uses straightforward and aggresive marketing language. The message is understood by simply reading the title: «The Principle is the Same... One Works Better...». This is not a detailed description of a machine but a presentation designed to convince you of superior money saving and efficiency. Like most such descriptions, word are chosen for one special purpose: to encourage the customer to buy.

Whatever your purpose, it is good practice to express it clearly at the very beginning, as shown in this more formal example:

A major objective of the TES investigation is to determine and map the mineralogy of the Martian surface in order to understand the formation and development of Mars. To understand present and past conditions on Mars, it is important to determine if the surface materials are, for example, volcanic, weathering products, or chemical precipitates. We demonstrate here that Martian dark materials are volcanic and that they vary significantly across the planet. These findings can help lead to an understading of planetary mechanisms such as the development of the Martian crust, heat loss processes, bulk composition, magma differentiation, and source materials of the Martian soil and dust ("A Global View of Martian Surface Compositions from MGSTES". Science (March 2000) vol. 287:1626).

Having the purpose clearly in mind helps to organise your thinking in a coherent way. Also, if that purpose is made evident to the audience, they will find it easier to understand the message. It is important therefore to be aware not only of the purpose underlying each piece of writing but also of the audience to which it is addressed. Hence, as Houp \& Pearsall report:

Identifying the audiences, their characteristics, and their needs is one of the most important jobs communicators have... it determines what kind of information must be provided and how it should be phrased (1992: 66). 


\section{The Principle Is The Same... It's Just That One Works Better.}

In induserial cleaning, the key is h:ivingt the right equipment, people and s'xpertibe to do the job right the furst time - safely and efficiently. There's a lot more to it than just scraping away

At Hydrochem our depth of resources makes the difference. With close 1050 offices nationwide, equipment and horsepower unmatched in our industry, and expertly trained personnel, no ocher company comes dose

From scale removal to degassing to corrosion control, HydroChem provid. the widest range of cleaning systems available. Prom exchangers to towers to reactor vessels, we have the horse. power and technology to dean more thoroughly and nore quickly thin an? wher indusural cleaning company

Whether it's elemical cleaning. hydroblasting, vacuum services, metal cutring, tank cleaning, waste minimiz: ion of other special services.

HydroChem's expertise is unmalched meaning more cleaning efficiency and dollar savings for your plant.

For more information about HydroChem's full line of inctustrial (deaning services, please call or write for a free brochure.

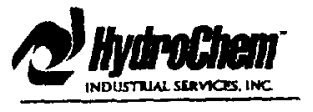

Providing Innowasive Solubions To Industrial Cleaning Problems.

6210 Rothway

Houston, Tenas 77040

(713) $462-2130$

(800) WE-CIEAN

Fax: (713) 329.2444

aww Hydrothenicum

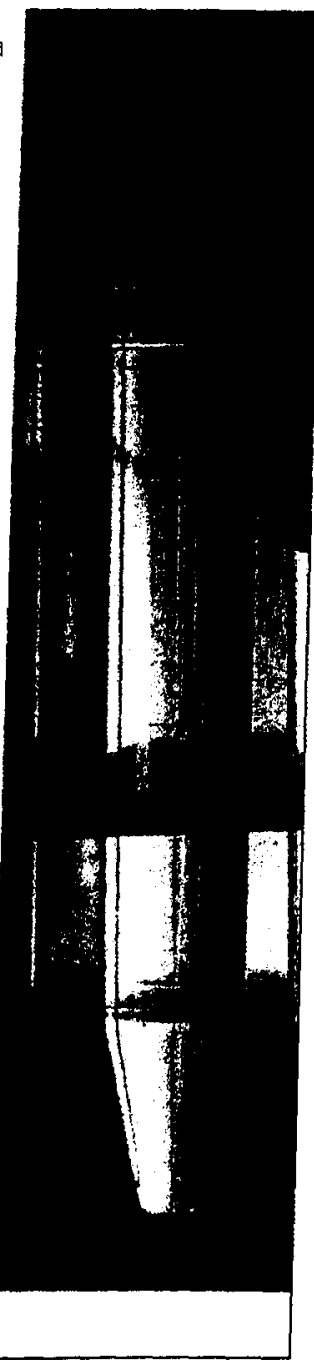

Figure 4. An example of a persuasive advertisement. 
Every form of text, every register of writing has conventions that both writers and readers must respect. If these conventions are ignored, communication fails. For instance, within any given company, one can expect to find technicians, specialists, managers, lawyers, and experts in marketing and finance, each group possesing a distinctive discourse structure. A report that does not take into account this particular structure and set of individuals is likely to be faulty and incomplete (see Bhatia 1994: 14).

As a general rule, graduates the same as professionals in science and technology will come across audiences with the concerns and characteriscs outlined in figure 5 below:

\begin{tabular}{|c|c|}
\hline AUDIENCE & CONCERNS AND CHARACTERISTICS \\
\hline Lay Persons & $\begin{array}{l}\text { - Read for learning and interest } \\
\text { - Have more interest in practice than theory } \\
\text { - Need help with science and mathgmatics } \\
\text { - Enjoy and learn from human interest } \\
\text { - Require background and definitions } \\
\text { - Need simplicity } \\
\text { = Learn from simple graphics }\end{array}$ \\
\hline Executives & $\begin{array}{l}\text { - Read to make decisions } \\
\text { - Have more interest in practice than theory } \\
\text { - Need plain language } \\
\text { Learn from simple graphics } \\
\text { - Need information on people, profits, and environment } \\
\text { - Expect implications, conclusions, and recommendations expiessed } \\
\text { clearly } \\
\text { - Read selectively-skimming and scanning } \\
\text { - Have self-interests as well as corporate interests }\end{array}$ \\
\hline Tochnicians & $\begin{array}{l}\text { - Read for How-To Information } \\
\text { - Expect emphasis on practical matters } \\
\text { - May have limitations in mathematics and theory } \\
\text { - May expect theory if higher level }\end{array}$ \\
\hline Experts & $\begin{array}{l}\text { - Read for how and why things work } \\
\text { Need and want theory } \\
\text { - Will read selectively } \\
\text { - Can handle mathematics and terminology of field } \\
\text { Expect graphics to display results } \\
\text { Need new terms defined } \\
\text { - Expect inferences and conclusions to be clearty but cautiously ex- } \\
\text { pressed and well supported }\end{array}$ \\
\hline Combined & $\begin{array}{l}\text { - One person may combine the attributes of several audiences } \\
\text { - Readers may consist of representatives of several audiences }\end{array}$ \\
\hline & Hience Concerns \\
\hline
\end{tabular}

Figure 5. Audience Concerns (Houp \& Pearsall 1992: 51). Reprinted by permission of John Wiley \& Sons, Inc. 
Writers must determine who the reader is an then decide how to meet their needs and concerns. Most of the time they will not have one particular audience (mostly specialists) but a combined audience, that is, a team of people consisting of executives, experts and lay readers. Hence they will need to consider several types of reader at once and try to meet their expectations, needs and interests as closely as possible.

\section{WRITING SKILLS AND STRATEGIES FOR COMMUNICATING SUCCESSFULLY}

What to include in a document - and how to arrange it - is dictated largely by the intention in writing it. Do you want your readers simply to read and understand the text, but not necessarily to remember the information? If so, providing key words and phrases, devising a concrete layout to highlight relevant points and creating summarising paragraphs or tables will not be necessary to help them retain the information you are presenting. But if you are trying to inform about a particular device, you will have to use these and other tactics. It won't be enough just to present the material in a way that allows the reader to skim it and gain an overview of what you are proposing. Information has to be laid out in a different way to explain how the device is built, how it works, how to use it, and so on.

Although these different purposes (description, definition, instruction, argument...) may appear at some point in various types of writing tasks, both the order in which they appear and the amount of detail will vary. In fact, good communication relies on appropiate SELECTION and ORGANISATION of content.

Especially for readers of scientific and technical literature «... writing is meaningful to the extent that it provides the information they need, located where they can quickly find it, in a form in which they can easily use it» (Huckin \& Olsen 1991: 395). Writers in this field should, then, do everything possible to make the information in their writing clear, accessible and useful to the potential reader.

All too often, they are expected to produce different types of texts/genres immediately from and outline or even a draft, without being given the opportunity to gather an organise the material they will use in their documents. In my opinion, more attention should be given to the pre-writing stage, where information skills are imperative to grasp.

The two basic skills that should serve as a starting point in the writing process are: to select information appropiate to the audience; and to organise/structure information so that it meets the reader's needs. After selecting and organi- 
sing information in the early stage of the writing process, the stages of drafting, revising and editing the document follow.

\subsection{Selecting information}

Selecting information appropriately appears to be a common weakness in scientific and technical writing. Many times the message conveyed by the writer is too blurred by irrelevant and superfluous detail. The first step before any writing is produced is to discover the material that will be used in the composition. Of course, not all the material needed can be assumed knowledge at the start. You have to resort to other sources (such as bibliographies, letters of enquiry, asking experts on the topic...) to fill in the gaps in your knowledge and gather enough information on the subject.

According to Houp \& Pearsall, brainstorming about a subject seems to be the best way to start the ball rolling. At this initial stage, there should be no attempt to evaluate or arrange the material because that may cause you to discard an idea that may prove valuable. All that has to be done is to bring ideas and facts out in the open, where they can be considered and analysed.

Later on, it is useful to employ standard arrangement patterns as aids to develop the material. For example, if your purpose is to instruct your reader how to operate a machine, an instruction pattern - often shown in catalogues and brochures - may help brainstorm your material in a more guided way. You know that a set of instructions often lists and describes the tools that must be used and also states the steps of the procedure in a chronological order. Therefore, you will begin jotting down initial thoughts and ideas that come to mind in accordance with an intruction format.

In my current occupation, students often ask for guidance when they have to write letters to apply for grant or a job. They know how to address a friend or relative but they fail to identify the type of information and language that should be included in formal correspondence. This is a genre where discovery techniques are essential to select the kind of information required for a well-presented piece of writing.

In the doctorate course I teach at the School of Mining Engineering, the class was first given a sample of a formal letter of application to work on proof-reading (see appendix 1). The students were then asked to correct and rewrite it according to the criteria of application letters format (shown in block capitals. Figure 6). This is one example produced by them:

This is a good example of a letter composed in accordance with the steps of the selection process. In the planning stage, the students were re- 


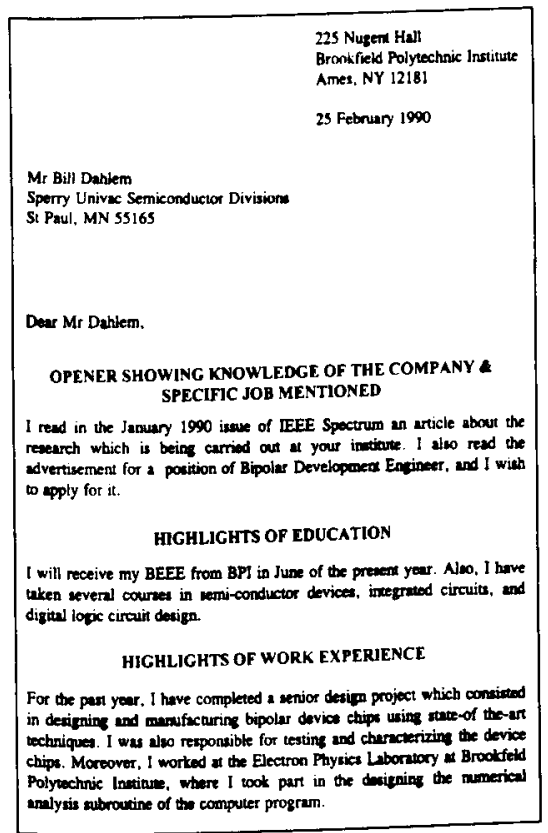

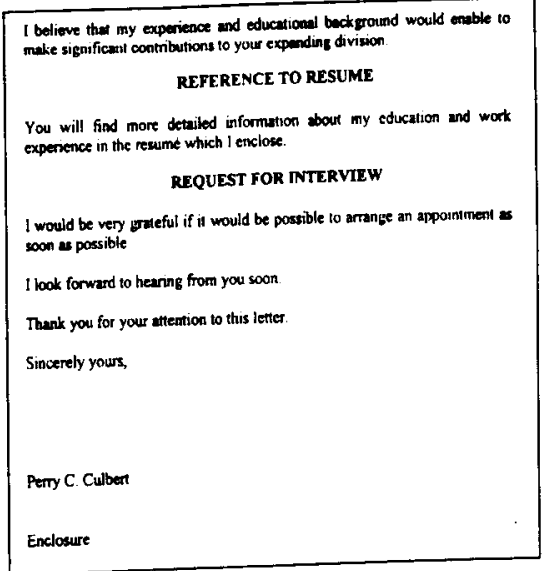

Figure 6. Example of a student's letter.

minded that the main communicative purpose of the job application letter is persuasive, so that they became aware of the primary intention that should dictate their writing, i.e. to persuade someone to give them the job. This in turn determined the formal style and rules of appropriacy used in this sort of correspondence.

Then, when they started brainstorming and jotting down the initial ideas and statements that came to mind, they had to select their material using a specific arrangement pattern, which governed the layout and information conventions of a formal cover letter. This pattern corresponded to the following sections:

1) Opener showing source of information about the job \& specific job title.

2) Highlights of education and work experience.

3) Reference to resumé.

4) Request for an interview.

At the beginning of the sample letter, the writer states the source of information for the job: he has been interested enough in the company to re- 
search its activities. The middle portion poinpoints his qualifications and work experience that relate directly to the job sought; then he refers the reader to his resumé. And in closing, he hints at the possibility of an interview.

It is clear that the compostion of the document has been preceded by a task of preparation. Selection of information is therefore vital to the writing process. In this prewriting stage, after urging students to brainstorm a specific isue to generate ideas and work out a plan as highlighted in the sample letter, they will head for the appropriate selection of high priority information in accordance with the contents and format of the document, followed by a sensible ordering of main points and supporting details. An effort has been made to contextualise the letter, considering the concerns, needs and interests of both the addresser and addresee.

\subsection{Organising Information}

Just as there is an arrangement pattern for the application letter, there are other definite arrangements for different documents (some of them etablished as proper genres), which may serve as models to structure a text.

Developing adequate schemata for the structures of determined texts is an essential prerequisite for the production of a piece of good prose. After examining mining engineering students' written work for the last five years, I have come to the conclusion that they need to be taught how to arrange information appropriately in a piece of writing. Students must learn that writing in English is not simply a question of relying on an accurate translation of their sentences from their mother tongue into English; but that the organisation of written discourse has its own conventions. They should be helped to learn this schema right from the start of the writing process.

Consequently, the very first thing they should be aware of is that, in any piece of writing in English, it is common practice to state the topic (that is, the main idea, focus or point of view), and then determine the best squence in which their ideas shoul be presented. They should choose an arrangement pattern: instructional, chronological, comparison, classification, analysis, cause and effect and so on, all of them acting as supporting details to the main statement made. Each of these patterns has in turn certain characteristic features, and by using these, they can make it easier for the reader to process the text as $a$ unified whole.

In order to develop an awareness of the conventional construction and use of different types of written communication and their discourse organi- 
sation, writers have to be sufficiently exposed to a wide range of texts. Said texts exhibiting such features and especially those genres with a distinctive discourse structure as will be used in their academic and professional contexts.

I have chosen the ABSTRACT -representative of the research genreto illustrate this principle, since it is an essential document within the academic world. Its main function is to summarise and highlight the major points of the investigaion so that the prospective reader can decide if it is in his interest to read the article in full. It has the following structure:

- The first part (a few sentences) presents the reasons for the study what the objectives were- - and states what exactly was studied (PURPOSE and SCOPE of investigation).

- The method is exposed but no focused on in any detail (METHODS).

- The middle part - the largest in space-- describes actual results and conclusions (major FINDINGS and principal CONCLUSIONS).

- The last part (this is optional) discusses implications of findings and makes recommendations (RECOMMENDATIONS).

Abstracts can be descriptive or informative. The former is designed to indicate the subject of a paper (and possibly methods used to arrive at the findings), making it easy for potential readers to decide whether or not to read the paper. The informative abstract, on the other hand, is designed to encapsulate the paper. It can and should briefly state the problem, the method, the results, the conclusion and recommendations, if any. This type of abstract retains the tone and essential scope of the original work while omitting its details.

To complete their studies, students of science and technology at Spanish universities have to write an abstract - presumably informative- of their senior year project in English. After reviewing samples of their abstracts, we have noted that for the most part the English is poor and the work itself does not follow the format mentioned above. In my experience, students do not know how to write informative abstracts, which are those requested for scientific writing. Thus, they tend to present the topic merely followed by a simplified outline of the work done.

Students of the doctorate course were asked to read an article entitled «SPECTRA: A Signal Processing Engineering Curriculum» (See IEEE Transactions on Education 39/2: 180-5. May 1996). Then they had to write their own abstract. Below is an example of a student's work: 


\begin{abstract}
In traditional engineering learning enviroments, real-world problems are too often ignored or reduced to trivialized case studies. SPECTRA is a new class of technology-based educational delivery system for the study of digital processing (DSP) that can emulate a real engineering experience. This paper will develop the SPECTRA philosophy and methodology and then demonstrate its impact on two new undergraduate and graduate level DSP courses. The several learning innovations of SPECTRA have produced promising results that will be quantified in the future as the curriculum evolves.
\end{abstract}

Figure 7. A student's version of an abstract.

Although topic and purpose have been stated in the first lines, this abstract simply reports on the new technology-based system called SPECTRA for the study of DSP education, which has proved to be successful in an engineering learning environment. The methods employed to carry out the investigaion are not mentioned. Neither does it define the DSP innovations introduced by this system. The conclusion limits itself to promising future results.

The abstract is meant to give the reader an exact and concise knowledge of the full article. But the reader of this abstract would lack information regarding the methods and the achievements of the study. Therefore, he will have to move on to the main body of the research looking for these items. To write an informative abstract, organisational patterns are critical and thus students must learn the structure mentioned previously (p. 385).

In order to properly organise the main ideas of their projects within the typical format and conventions of an abstract, we can introduce them to several strategies or tactics that have proved useful in the classroom, as noted by this author, linguistic experts and writing trainers (Carino 1993; Porush 1995; Swales \& Feak 1997).

\title{
3.2.1. To recognise the purpose or principal activity of the investigation
}

This is one of the most important sections or «moves» of the abstract and should be stated clearly so that the reader learns right from the start what the document is about. The author must begin with a thesis or hypothesis that forms the basis of the research being reported. 
e.g. «This paper sets out to examine..»

"This investigation provides an analysis...»

«This study provides evidence for the hypothesis that...»

Students sometimes do not state the purpose clearly, so the reader has to proceed to other sections of the report to work it out.

\subsubsection{To distinguish between facts and opinions}

Opinions in scientific and technical writing, unlike those in everyday social conversation, are educated guesses. They are arrived at after some study or observation has taken place. Although an opinion has not yet been proved, it might be in the future. A fact, on the other hand, may be demonstrated or has already been proved. Once proved, facts are accepted and considered to be true.

When writing an abstract, it is necessary to decide which facts presented in the report must be included and summarised briefly and which statements are only opinions. Students sometimes take the conclusions of studies to be irrefutable facts and they put them forward in the abstract, without realising that they may be only educated guesses. Therefore, they should not be presented as basic arguments (or macro-propositions) of the research.

This is the case of another student on the doctorate course who wrote an abstract of the Spectra article. The authors say in the summary of the report:

«The use of personal CBI has seemed to produce measurable and desirable results".

a statement which is merely an opinion whereas he quotes it as a given fact:

«Spectra technology as seem now is producing promising results».

3.2.3. To communicate a crucial piece of information in every sentence

Crucial means that, by leaving out specific items of information, the abstract will not be a precise overview of the contents of the article/report. 
Students need to discern essential data corresponding to the principal "moves» of this genre, and condense the minimum necessary information for the reader to understand most significant aspects of the investigation.

\subsubsection{To maintain the same level of generality throughout}

Writing an abstract is an important cognitive exercise that serves to condense information in order to provide a concrete view of the research. Therefore, it should be written in general terms without any reference to the text of the paper itself, as in the following:

e.g. X: "The information of this paper came from the results of ...»

$\mathrm{X}$ : "As the data this paper presents will show..."

$\mathrm{X}$ : «Waste heat recovery can be used to produce saturated or superheated steam as, for example in combined cycle application...".

\subsubsection{To use models}

Models or examples taken from other bibliographical or study sources can help students analyse how information is arranged in a specific way within a genre. In the case of an abstract, they may consult other dissertations or final year projects with a view to:

- Reading and thinking about the content - that is, the information included, how it is presented and summarised in relation to the research.

- Looking closely at the language used in addition to the style, so that they may underline or make notes of any useful expressions and sentence structures to be employed in their own abstracts.

- Examining the organisation and development of ideas following the concrete «moves» of an abstract, which may guide the ordering and structuring of the most salient points of their own research reports.

In order to write a good abstract from the article mentioned above, doctorate students were previously provided with several samples of abstracts which they analysed for format, contents and language. After applying these strategies, they came up with a superior final product, such as in this example: 


\section{SPECTRA: A Signal Processing Engineering Curriculum}

At present, it seems to be that new technologies should be introduced into the educational process in order to adapt the academic experience to the actual needs of industry. It is important to change the emphasis from knowing to reaching some goals suchas as: supporting cooperative learning, group problem-solveing and hands-on education. In this frame, SPECTRA was developed like a technology-based comprehensive engineering educational delivery system for the study of digital processing (DSP). SPECTRA introduces a number of DSP education innovations into the classroom, including a commitment to cooperative learning and a reliance on personal computer-based instructional (CBI) tools and technologies. This paper will develop the SPECTRA philosophy and methodology and then demonstrate its impact on new undergraduate and graduate level DSP courses. Personal CBI tools were used in class to show virtually every major topic and then used by students to solve challenging programs that were parametrized to appear as a wireless communication problem. The use of personal CBI has produced measurable and desirable results. In the future, these results will be quantified as the curriculum evolves.

Figure 8. Revised version of the abstract.

As can be seen, this student has introduced the subject of the investigation in his abstract by means of background information about SPECTRA. This is immediately followed by a clear statement of the purpose or principal activity of the paper. The next «move» is a sentence explaining the tools (methods) used to obtain specific goals. Major findings are not explained because the paper itself does not give enough data to show the outcome of the research. The only reference to a conclusion is a sentence indicating quantifiable results in the future.

In any case, the student states facts in every sentence; no opinions are given. He follows the «moves» or sections of the informative abstract closely, communicating the essential data of the report. He never alludes to the main text of the paper but maintains generality throughout. And finally, it can be seen that he has endeavoured to condense the salient information of the source article into the principal «moves» of the abstract, imitating other sources studied previously. 
In sum, all the prewriting strategies are directed at focusing attention on the structure and organisation of the material to be processed, in such a way that students become able to reproduce its main generic features and eventually compose an acceptable piece of written work.

\section{Conclusion}

Higher education must concern itself with preparing students to communicate effectively. Unfortunately, the standard of communication in the field of science and technology is generally considered to be disturbingly low not only in writing, but also in oral interaction with other professionals. Despite the fact that the primary training and interest of scientists and technologists lie in technical areas, unless they can communicate what they are doing and why it is important, they will be unable to put their knowledge to effective use.

In this context of higher education -especially at university levelCommunication Skills training is essential. Not only does it enable students to communicate clearly for the purpose of their academic studies, but also prepares them for the wide range of communication tasks and situations that they will face as graduates in their future occupations.

Communication Skills training deals with subjects like the techniques and structures of technical writing as well as the techniques of effective oral preentation and other managerial skills. Technical writing is foremost among the skills required both in academic and professional settings.

At university, right from the start, undergraduates are judged by their coursework (essays, records of experiments, project reports, theses) and by performance in written examinations. Only by writing well can they give a good account of themselves as students, applicants for employment, and as employees: writing letters, instructions, reports, articles and scientific papers for publication.

In the future, professionals in this field will be faced with a wider and much more diverse set of written tasks. These will demand: 1) an increased ability in the structuring and arrangement of data, ideas, diagrams... as they acquire and display specialised technical knowledge; 2) the ability to present their material, views and proporsals in a meaningful and accessible way; and finally, 3) information gathering skills and creativity.

In this respect, information skills are essential in the writing process, especially in its early stage. Failure to select information appropriately is a common weakness in scientific and technical writing. Often, writers blur their messages by giving too much information that is irrelevant or superfluous. They do not 
discriminate between what is really relevant and what is only mildly interesting. The emphasis throughout the selection process must be on the needs, concerns and interests of the readers as well as the purpose of the document being composed. The audience plays a crucial role in defining the kind of information provided and the way it should be delivered. But it is vital to do more than just make information convenient to receive. It must comand the reader's attention. That is, it should be presented in a way that is accesible and useful. Therefore, information must also be arranged: important data has to be highlighted by careful ordering and emphasis. This whole process of SELECTING and ORGANISING information is one of the most necessary Communication Skills which needs to be taught in English for Science and Technology.

In short, to become better communicators, writers in this sphere should not only be able to recognise and use the conventions and formats established within different types of texts/genres, but also given the critical tools for success. Hence Communication Skills are the tools to achieve a more effective and productive transmission of their technical knowledge.

\section{REFERENCES}

Bhatia, Vuay K. (1994): Analysing Genre: Language Use in Professional Settings. New York \& London: Longman.

CARINo, P. (1993): The Research Paper Simplified. Indiana State University: Harper Collins College Publishers.

Hendricks, Robert W. \& Eric C. PAPPAS. (1996): Advance Engineering Communication: An Integrated Writing and Communication Programme for Materials Engineers. Journal of Engineering Education 85/4: 343-52.

Houp, Kenneth W. \& Thomas E. Pearsall (1992): Reporting Technical Information. New York: MacMillan Publishing Company.

Huckin, Thomas N. (1994): Seminar on Technical Writing for Engineering Environments. V Jornadas de Investigación held by the Departament of Linguistics Applied to Science \& Technology. Universidad Politécnica de Madrid.

Huckin, ThOMAS N. \& LeSLIE A. OlSEN (1991): Technical Writing and Professional Communication for Nonnative Speakers of English. New York: McGraw Hill Book Company.

Jenkins, Susan, Mary Kaye Jordan \& Patricia O. Weiland (1993): The Role of Writing in Graduate Engineering Education: A Survey of Faculty Beliefs and Practices. English for Specific Purposes 12: 51-67.

KeEnAN, A. \& T. Newton (1984): The Training of Engineers: Undergraduates' preferences and Subsequent Experiences in Employment. International Journal of Electrical Engineering Education 21:213-20. 
KIRKMAN, JoHN (1992): Good Syle. Writing for Science and Technology. London: E \& FN SPON.

Palacios Martínez, Ignacio M. (1994): La Enseñanza del Inglés en España a debate. Universidad de Santiago de Compostela: Servicio de Publicaciones e Intercambio Científico.

PORUSH, DAvID (1995): A Short Guide to Writing about Science. New York: Harper Collins College Publishers.

RaIlgon, Diana (1984): Approaches towards Technical Communication Skills Training in British Higher Education: with Particular References to Engineering. Language Studies Unit Research Report. Dpt. of Modern Languages. Birmingham: University of Aston.

Swales, John M. \& Feak, Christine B. (1997): Academic Writing for Graduate Students. A Course for Nonnative Speakers of English. The University of Michigan: Ann Arbor.

TURK, ChristoPHER \& JOHN KIRKMAN (1992): Effective Writing. Improving Scientific, Technical and Business Communication. London: E \& FN SPON.

Weissberg, Robert \& Suzanne Buker (1978): Strategies for Teaching the Phetoric of Written English for Science and Technology. Tesol Quarterly 12/3: 321-9. 


\title{
APPENDIX 1
}

\author{
226 Nugont Hall \\ Brookneld Polytechnic Institute \\ Ames, NY 12181 \\ (B55) 270.4391
}

Febuary 25, 1890

Mr. Bill Dahlen

Sperry Untvac Semiconductor Dfvistons

प2X26, P.O. Box 3526

St. Paul, MN 55165

Dear Mr. Dahlem:

In response to your advertisement in IIEEE Bpectrum (August 1990), I am writing to apply for the position of Bi-polar Developement Englneer. Arter considering Jour challenging requirements; I believe that my experience and ectucational background would enable to make significant contributions to your expanding diviodon. My backround includes-

Employment by the Electron Physisc Laboratory, Brookfold Polvtechnic Institute. I participated in designing an innovative computer modeling process of a MOS submicron devise. I was responsible for designing the numerical analysis subroutines of the computer program.

Completion of a senior desing project in designing and fabricating bi-polar device chips using state-of-the art tochnice. I was also responsable for tosting and characterizing the device chips.

Completion of several graduate courses in seml-conductor dovices, lnterersted circtuts and digital logic circult dosign.

I will recieve my B.S.E.E. trom BPI in August 1990 and would approciate being considered for permanant employment starting therator. I will call on you next wed. during your oflece hours to set up an interviow at your convience. If you desiro additional information, I can be reached at (555) 270-438 I durtng the mornings.

Thank you for your kind consideration.

Yours truely,

Perry C. Culbert 